\title{
The Effects of Self-Focused Attention on Mood: Differences of Self-Aspect Valence while Self-Focusing
}

\author{
Rie Tabuchi' ${ }^{1}$, Asami Yamazaki², Megumi Oikawa ${ }^{2}$ \\ ${ }^{1}$ The United Graduate School of Education, Tokyo Gakugei University, Tokyo, Japan \\ ${ }^{2}$ Faculty of Education, Tokyo Gakugei University, Tokyo, Japan \\ Email: r162002p@st.u-gakugei.ac.jp
}

How to cite this paper: Tabuchi, R., Yamazaki, A., \& Oikawa, M. (2017). The Effects of Self-Focused Attention on Mood: Differences of Self-Aspect Valence while SelfFocusing. Psychology, 8, 1414-1423. https://doi.org/10.4236/psych.2017.89093

Received: May 24, 2017

Accepted: July 24, 2017

Published: July 27, 2017

Copyright ( 92017 by authors and Scientific Research Publishing Inc. This work is licensed under the Creative Commons Attribution International License (CC BY 4.0).

http://creativecommons.org/licenses/by/4.0/ (c) (i) Open Access

\begin{abstract}
Self-focused attention is a primary risk factor for depression in adolescents. Previous studies have suggested that sustained self-focus ultimately leads to depression. However, in recent years, it has been suggested that focusing on all aspects of the self, both positive and negative, has a positive effect on mental health. Hence, in this study, we aimed to explore adaptive self-focusing and examined the effects on mood following manipulation of the self-aspect (i.e., both positive and negative aspects of self, only positive, and only negative). Eighty-eight Japanese undergraduate and graduate students participated in the experiment. Results suggest that focusing on both positive and negative aspects of the self does not amplify depressed mood. Furthermore, this type of self-focus also does not decrease positive mood, and exhibits the same adaptive effects on mood as focusing only on positive aspects of the self.
\end{abstract}

\section{Keywords}

Self-Focused Attention, Depressed Mood, Positive Mood, Self-Aspect

\section{Introduction}

In adolescence, mental disorders, such as major depressive disorder, anxiety disorder, and schizophrenia are more likely to develop or manifest (Sawazaki \& Matsubara, 1988). Previous studies have reported that university students in late adolescence are often highly depressed (Tomoda, Mori, Kimura, Takahashi, \& Kitamura, 2000; Garlow, Rosenberg, Moore, Haas, Koestner, Hendin, \& Nemeroff, 2008). For instance, approximately $70 \%$ of Japanese university students display depression greater than or equal to mild, and approximately $10 \%$ demonstrate the same degree of depression as found in severely depressed patients 
(Murayama \& Okayasu, 2012). Therefore, prevention of depression that targets adolescents has become an urgent issue, and thus, preventive interventions have begun to be developed (Peden, Rayens, Hall, \& Beebe, 2001; Oikawa \& Sakamoto, 2008).

Self-focused attention is one of the possible risk factors of depression in adolescents. Self-focused attention is both the state of paying attention to oneself, and the personality trait of an individual that tends to readily pay attention to him/herself (Sakamoto, 1997). Establishment of ego identity is an important developmental task in adolescence. As such, this developmental task presents individuals more opportunities to think about who they are, and what kind of person they would like to be. Therefore, self-focused attention increases (Sakamoto, 1997; Kosaka, 2009).

According to Self-awareness Theory (Duval \& Wicklund, 1972), an individual evaluates him/herself by comparing the ideal self with the actual self. This reflection occurs, not surprisingly, in a state where attention is focused on the self. Young people tend to be especially conscious of the gap between ideal and actual self, and are also more likely to focus on negative aspects of the self. Thus, self-focused attention is often negative, resulting in increases of depression and anxiety (Sakamoto, 1997). It has been reported that university students tend to engage in negative self-focusing (Murayama \& Okayasu, 2012). In previous studies related to depression, it has been considered effective to limit sustained self-focus, as this leads to depression (see review Nolen-Hoeksema \& Morrow, 1993; Sakamoto, 1993). However, to establish identity, it is necessary for an individual to reflect upon who they are in order to acquire the confidence that he/ she is developing a personality that can be clearly positioned in social reality (Erikson, 1959). To think about themselves and to wonder what kind of person they are in society are important tasks that cannot be avoided for young people. Therefore, it is essential to provide support for adaptive self-focused attention that does not lead to depression to prevent the occurrence of this mental health issue in late adolescence.

Some studies in university students have demonstrated that the higher tendency to resist examining negative aspects of the self, the higher feelings of self-disgust, while there was no relationship between the amount of opportunities of self-focusing and the amount of self-disgust (Satoh \& Ochial, 1995). From these results, Satoh \& Ochiai (1995) also suggested that the extent to which negative feelings toward the self are experienced is not related to the amount of opportunities of self-focusing, but rather, how an individual engages with the self (i.e., whether the individual thinks about the negative parts of the self). Additionally, the more deeply an individual looks at the self, based on both positive and negative aspects, the lower the feelings of inferiority, although a higher tendency to distract oneself from the negative aspects, the higher feelings of inferiority (Kosaka, 2009). Furthermore, Mizuma (2003) has pointed out that the turning point of whether individuals fall into depression, or participate in self-formation when experiencing negative events is to look directly at the nega- 
tive aspects of the self and view it as a problem. These findings suggest that, in adolescence, it is important to consider which aspect of the self to focus upon for self-focusing to become adaptive, and that focusing on both positive and negative aspects is necessary.

The study focused on two dimensions of the self (positive/negative) when self-focusing, as it has been suggested that individuals who pay attention to both sides when self-focusing do not demonstrate decreases in self-evaluation, even if attention to the negative aspects of the self continues (Harada, 2006). Additionally, it has been suggested that attention paid to both the positive and negative aspects of the self provides a buffer from the depression that typically results from only a negative self-focus (Kumada \& Oikawa, 2015). These findings suggest that it is possible to adaptively engage in self-focusing, without increasing depressed mood, by combining attention to both the negative and positive aspects when self-focusing. However, the aforementioned studies primarily utilized survey methodology. As such, empirical studies on the effects of attention to both sides of the self on mood are still insufficient. Thus, in the current study, we aimed to explore adaptive self-focusing and experimentally examined the effects of manipulation of the target aspect of the self when self-focusing on mood.

\section{Methods}

\subsection{Participants}

The experimenter explained the outline of this study in university classrooms and asked for those who were willing to participate. The sample of this study consisted of 88 Japanese undergraduate and graduate students (41 men and 47 women). The mean age was $20.81(S D=1.53)$. All participants belonged to the same university.

\subsection{Measures}

\subsubsection{Depressed Mood and Positive Mood}

The Depression and Anxiety Mood Scale (DAMS; Fukui, 1997) consists of three subscales: depressed mood, anxious mood, and positive mood. In this study, only depressed mood and positive mood were used. Depressed mood is comprised of three items "depressed," "disgusted," and "dark," while positive mood is characterized by "fun," "active," and "happy." The degree of each item is rated on a seven-point Likert type scale (i.e., $1=$ not at all to $7=$ very applicable). The DAMS has demonstrated sufficient reliability, convergence validity, and discriminative validity (Fukui, 1997).

\subsubsection{Private Self-Awareness}

To ascertain whether the subjects' attention was focused on themselves during the self-focus task, the Private Self-awareness Scale was used as an operation check. This scale aims to measure the state of private self-awareness, and is comprised of 9 items (e.g., "I was trying to understand what kind of person I 
was," "I focused attention on my true feelings"). The degree of each item is rated on a seven-point Likert type scale (i.e., $1=$ not at all to $7=$ very applicable). Reliability of this scale has been shown to be adequate and internal consistency has been supported (Sakamoto, 1993).

\subsection{Self-Focus Task}

The manipulation of self-focus conducted in previous study (Sakamoto, 1993) was utilized in the current study. The manipulation of self-focus (Sakamoto, 1993) is aimed at inducing thought about one's own inner personality, and is composed in a style similar to the "Who Am I?" test (Kuhn \& McPartland, 1954; Furusawa \& Hoshino, 1962). Specifically, the manipulation is a task to describe 10 different answers to the question "What kind of person am I?" for 6 minutes. To raise the attention to the private self, answers are restricted to contents concerning one's own inner characteristics, and it is instructed that participants should not to answer about external aspects (e.g., appearance, clothes, etc.) or social aspects (e.g., blood relations, affiliations, etc.). In other words, this task is a method for individuals to ask themselves "What kind of person am I as a whole?" through the completion of 10 different answers.

In the present study, the operation of the valence of self-aspect in self-focus was added to the manipulation utilized by Sakamoto (1993), and the three conditions were set: both-aspects group (focus on both positive and negative aspects of the self), positive group (only on positive aspects of the self), and negative group (only negative aspects of the self). The subjects in the both-aspects group were asked to complete sentences such as "I like my " and "I do not like my ___, alternately. The subjects in positive group completed only sentences of "I like my ___, and subjects in negative group completed only sentences of "I do not like my__.." To maintain self-focus for 6 minutes, it is instructed to keep thinking about "What kind of person am I?" until the end of the experiment, even after completing all sentences.

\subsection{Distraction Task}

For ethical reasons, the distraction task was introduced so as not to sustain the subjects' negative moods after the experiment. We conducted a "connect the dots" puzzle as a distraction task. The puzzle used in this study asked participants complete a flower picture by connecting points, numbered 1 to 93 , in order, and with straight lines. A time limit was not set, allowing for the task to be completed at the pace of each subject.

\subsection{Study Procedure}

Participants were randomly assigned to three conditions, which were different in the self-aspect focused upon during the self-focusing task: both-aspects group ( $n$ $=29)$, positive group $(n=30)$, and negative group $(n=29)$.

This study utilized three measurements to evaluate changes in the mood of subjects during the experiment. First, subjects completed the DAMS to deter- 
mine baseline (Time 1). Next, after completion of the self-focusing tasks, the DAMS and Private Self-Awareness scale (Sakamoto, 1993) were completed (Time 2). Finally, after a distraction task, the DAMS was completed again (Time 3). The efficacy of the distraction task was confirmed in that each mood had recovered to the same degree as at the baseline. Experiments were conducted individually in university classrooms, and the experiment took approximately 20 minutes to complete. This study was carried out with the approval of the ethics committee of the affiliated university.

\section{Results}

\subsection{Manipulation Check}

The mean score of the Private Self-awareness Scale of all subjects was 42.57 ( $S D$ $=6.02$ ). Those whose score was $2 S D$ or more below the mean score were considered to have not been sufficiently induced to self-focus during the tasks. Thus, four subjects whose score was 30.53 or less were excluded from further analysis. Therefore, the total number of subjects to be analyzed was 84: both-aspects group $(n=27)$, positive group $(n=28)$, and negative group $(n=29)$.

\subsection{Condition Effects on Change in Depressed and Positive Mood}

Reliability, in terms of internal consistency, was high for each subscale ( $\alpha=0.88$ for depressed mood; $\alpha=0.85$ for positive mood). The mean scores of depressed mood and positive mood at each period, from Time 1 to Time 3, in each group, are displayed in Table 1. Changes related to self-focus in each mood were analyzed by a 3 (group: both-aspects group, positive group, and negative group) $\times 2$ (time: T1 and T2) mixed-model, two-way ANOVA (Figure 1).

For depressed mood, the interaction between group and time was significant $[F(2,81)=5.73, p<0.01]$. As a result of a Bonferroni's main effect test, the main effect of time in the negative group was also shown to be significant $[F(1,81)=$ 17.47, $p<0.001$ ], with depressed mood increasing at Time 2 compared to Time 1. The main effect of time was not significant in the both-aspects and positive groups $[F(1,81)=0.22$, n.s.; $F(1,81)=0.48$, n.s. $]$. In addition, the main effect of group at Time 2 was significant $[F(2,81)=3.96, p<0.05]$, with depressed mood being shown to be significantly higher in the negative group than positive group

Table 1. Means and standard deviations of each mood.

\begin{tabular}{ccccccccccc}
\hline & \multicolumn{3}{c}{$\begin{array}{c}\text { Both-aspects group } \\
(n=27)\end{array}$} & \multicolumn{3}{c}{$\begin{array}{c}\text { Positive group } \\
(n=28)\end{array}$} & \multicolumn{3}{c}{$\begin{array}{c}\text { Negative group } \\
(n=29)\end{array}$} \\
\cline { 2 - 11 } & Time & Time & Time & Time & Time & Time & Time & Time & Time \\
& $\mathbf{1}$ & $\mathbf{2}$ & $\mathbf{3}$ & $\mathbf{1}$ & $\mathbf{2}$ & $\mathbf{3}$ & $\mathbf{1}$ & $\mathbf{2}$ & $\mathbf{3}$ \\
\hline Depressed & 9.96 & 9.67 & 8.15 & 8.79 & 9.21 & 8.11 & 9.62 & 12.17 & 9.90 \\
mood & $(4.49)$ & $(3.94)$ & $(3.78)$ & $(3.95)$ & $(4.59)$ & $(3.43)$ & $(4.48)$ & $(4.26)$ & $(4.02)$ \\
Positive & 10.70 & 10.56 & 11.96 & 10.54 & 9.86 & 11.21 & 10.41 & 8.59 & 10.83 \\
mood & $(3.40)$ & $(2.76)$ & $(2.93)$ & $(2.77)$ & $(3.40)$ & $(2.57)$ & $(3.92)$ & $(3.64)$ & $(3.32)$ \\
\hline
\end{tabular}

Note: The upper row shows means, and the lower row shows the standard deviations. 

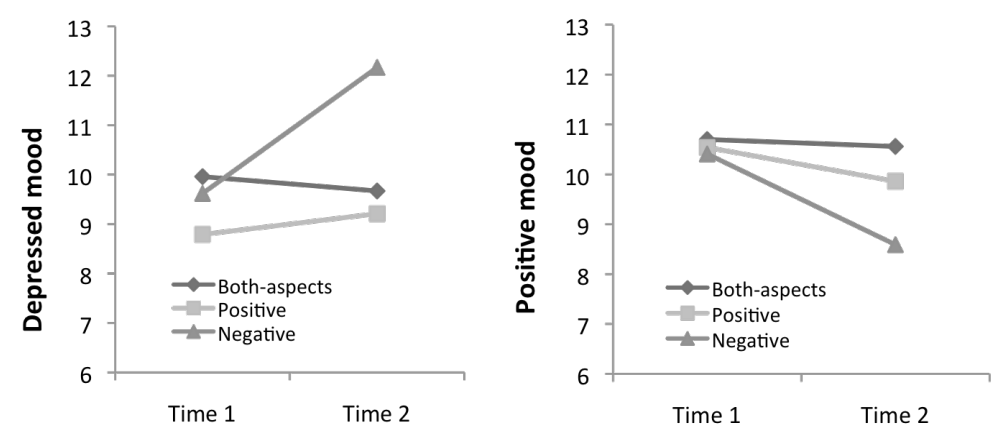

Figure 1. Change in mood after the self-focus task.

$(p<0.05)$. Moreover, a marginal difference was observed between the bothaspects group and negative group $(p<0.10)$. However, at Time 1 , the main effect of group was not significant $[F(2,81)=0.55$, n.s. $]$.

For positive mood, the interaction between group and time was significant $[F$ $(2,81)=3.31, p<0.05]$. The results of the main effect test showed that the main effect of time in the negative group was significant $[F(1,81)=15.39, p<0.001]$, with positive mood being shown to be significantly decreased at Time 2 compared to Time 1 in the negative group $(p<0.001)$. The main effects of time were not significant for the both-aspects and positive groups $[F(1,81)=0.09$, n.s.; $F$ $(1,81)=2.05$, n.s. $]$. However, the main effect of group at Time 2 demonstrated a trend towards statistical significance $[F(2,81)=2.58, p<0.10]$, with a marginal difference observed between both-aspects group and negative group $(p<0.10)$. At Time 1, a main effect of group was not observed $[F(2,81)=0.05$, n.s. $]$.

\subsection{The Recovery of Mood by the Distraction Task}

A 3 (group) $\times 2$ (time: T1 and T3) mixed-model, two-way ANOVA was conducted. For depressed mood, the interaction between group and time was significant $[F(2,81)=3.30, p<0.05]$. As a result of a Bonferroni's main effect test, the main effect of time in the both-aspects group was shown to be significant $[F(1,81)=9.60, p<0.01]$, with depressed mood being shown to be significantly decreased at Time 3 compared to Time $1(p<0.01)$. In the positive and negative groups, a main effect of time was not observed $[F(1,81)=1.39$, n.s.; $F(1,81)=$ 0.24, n.s.].

For positive mood, the main effect of time was significant $[F(1,81)=4.62, p<$ 0.05 ], with a significant increase observed at Time 3 compared to Time 1. Neither the main effect of group $[F(2,81)=0.49, n . s$.$] , nor the interaction of group$ and time $[F(2,81)=0.47$, n.s. $]$ was found to be statistically significant.

\section{Discussion}

The purpose of the current study was to examine the effects of self-focus on mood through manipulation of the attention paid to the valence of self-aspects during a self-focus session. This was done in an effort to obtain suggestions and data for support of an adaptive self-focusing method.

Results showed that individuals who focused upon both positive and negative 
aspects of the self (both-aspects group) and only positive aspects (positive group) did not display a significant increase in depressed mood following a selffocus task, and even maintained a positive mood. Conversely, individuals who focused upon negative aspects of the self (negative group) showed a significant increase in depressed mood, and a significant decrease in positive mood. Additionally, depressed mood after performing the task was observed to be lower in the both-aspects and positive groups when compared to the negative group, and positive mood was found to be higher in the both-aspects group when compared to the negative group. These results suggest that focusing on both the positive and negative aspects of the self is more adaptive than focusing only on the negative aspects. In the previous study (Kumada \& Oikawa, 2015), a weak negative correlation was shown between the tendency to focus on positive aspects of the self and depressive symptoms, a result that is mostly supported by the information gained from the present study.

From the current results, it was also shown that focusing on both self-aspects is adaptive to the same degree as focusing only on positive aspects, despite the negative focus that is included in this method. However, focusing on both positive and negative aspects of the self was not shown to be more effective in alleviating depressive symptoms when compared to individuals who focused only on positive aspects of the self. It has been suggested that, against emotions related self and self-worth, immediate actions, such as diverting attention from this focus is not effective, and that, conversely, not trying to look directly at the negative aspects of the self induces mental maladjustment and a sense of self-disgust (Satoh \& Ochial, 1995; Kosaka, 2009).

In this study, although there were no significant difference in the effects on depressed mood between both-aspects and positive groups, it is possible that differences may have occurred in other negative emotions, such as self-disgust. In addition, it has also been suggested that focusing on both aspects of self is related to the personality traits of displaying curiosity about the self and attempting to analyze oneself (e.g., reflection: Trapnell \& Campbell, 1999), which has recently been investigated as an effective form of self-focus for depression prevention (Takano \& Tanno, 2010; Kumada \& Oikawa, 2015). For example, it has been shown that those who tend to focus on both positive and negative aspects of the self have a higher tendency to reflect than those who focus on only one type of aspect (i.e. positive or negative only; Kumada \& Oikawa, 2015). Therefore, it may be possible that those with a high tendency to reflect reduce their depression by focusing both aspects of self. Thus, further investigation about the effects of focus on only positive self and both aspects is needed from the viewpoint of the influence on negative emotions other than depressed mood and with relation to reflection.

Results showed that a focus on only negative aspects of the self was the most maladaptive compared to other groups. In a previous study (Kumada \& Oikawa, 2015), it has been reported that those with a high tendency to focus on negative aspects of the self demonstrated higher rumination traits and depressive symp- 
toms when compared to those with a low tendency towards this behavior. Studies consistently report that negative self-focus leads to depression (e.g., Nolen-Hoeksema \& Morrow, 1993; Takano, \& Tanno, 2010). In this study, the mood of the negative group seemed to have deteriorated (i.e., increased depressed mood and decreased positive mood) as a result of inducing a ruminating state.

Finally, a distraction task was conducted as part of the ethical considerations of the project. Results showed that negative mood was not sustained in all groups. Therefore, it seems that there was no disadvantage to participants.

Some limitations of the current study should be addressed. First, participants' personality characteristics were not considered. In adolescence, self-focus is likely to be negative (Sakamoto, 1997), and there are many individuals at this stage who exhibit a high rumination trait (Murayama \& Okayasu, 2012). Even in this study, it was difficult for those demonstrating high rumination to focus on only positive aspects of the self. Therefore, it may have been possible that the effect was not sufficiently measured. Second, this study examined experimental effects over a short period of time. However, self-focus might occur repeatedly in various situations within everyday life. Due to these limitations, future research should examine the results obtained in this study in more detail. Specifically, analyses should be conducted taking into consideration personality characteristics, and the long-term effects of this positive/both aspect focusing should be explored through use of longitudinal measurements.

\section{Conclusion}

In conclusion, focusing on both the positive and negative aspects of the self does not amplify depressed mood, and has the same adaptive effects on mood as focusing only on positive aspects of the self. For adolescents, thinking about the self is an indispensable task required for self-formation. Therefore, it seems to be clinically significant to provide a method for adaptive self-focus. In the future, through further development of the current research, and application of these methods in the form of interventions that enhance adaptive self-focus that does not lead to depression, it may be possible to contribute to improving mental health in adolescents.

\section{References}

Duval, S., \& Wicklund, R. A. (1972). A Theory of Objective Self-Awareness. New York: Academic Press.

Fukui, I. (1997). The Depression and Anxiety Mood Scale (DAMS): Scale Development and Validation. Japanese Journal of Behavior Therapy, 23, 83-93.

http://ci.nii.ac.jp/naid/110009667965/

Furusawa, A., \& Hoshino, A. (1962). Stability of the Self-Attitudes. Educational Studies: International Christian University Publications, 1-A, 97-124.

http://id.nii.ac.jp/1130/00000497/

Garlow, S. J., Rosenberg, J., Moore, J. D., Haas, A. P., Koestner, B., Hendin, H., \& Nemeroff, C. B. (2008). Depression, Desperation, and Suicidal Ideation in College Students: 
Results from the American Foundation for Suicide Prevention College Screening Project at Emory University. Depression and Anxiety, 25, 482-488.

https://doi.org/10.1002/da.20321

Harada, M. (2006). The Relationship between Maintenance of Self-Focused Attention and Self-Evaluation: Conducted by Simultaneous Analysis of Several Groups. Kyoto University Research Studies in Education, 52, 253-265. http://hdl.handle.net/2433/43759

Kosaka, Y. (2009). Developmental Changes in the Style of Reflecting and Feeling of Inferiority in Adolescence. Japan Society of Youth and Adolescent Psychology, 21, 83-94. http://ci.nii.ac.jp/naid/110009484072/

Kuhn, M. H., \& McPartland, T. S. (1954). An Empirical Investigation of Self-Attitudes. American Sociological Review, 19, 68-76. http://www.jstor.org/stable/2088175 https://doi.org/10.2307/2088175

Kumada, M., \& Oikawa, M. (2015). The Effects of Positive and Negative Self-Focus on Reflection, Rumination, and Depression. Bulletin of Tokyo Gakugei University, Division of Educational Sciences, 66, 289-297. http://hdl.handle.net/2309/137850

Mizuma, R. (2003). Feelings of Self-Disgust and Self-Development: The Intention to Change the Negative Self. Japanese Journal of Educational Psychology, 51, 43-53.

https://doi.org/10.5926/jjep1953.51.1_43

Murayama, Y., \& Okayasu, T. (2012). Age-Related Changes in Depressive Rumination: Comparing Undergraduate Students and Adults in Their Thirties and Forties. Japanese Journal of Behavior Therapy, 38, 215-224. http://ci.nii.ac.jp/naid/110009595580/

Nolen-Hoeksema, S., \& Morrow, J. (1993). Effects of Rumination and Distraction on Naturally Occurring Depressed Mood. Cognition and Emotion, 7, 561-570. http://dx.doi.org/10.1080/02699939308409206

Oikawa, M., \& Sakamoto, S. (2008). Preventing Mental Health among Undergraduates: The Effects of Using a Revised Primary Prevention Program for Depression in University Classes. Kyoto University Researches in Higher Education, 14, 145-156. http://hdl.handle.net/2433/70820

Peden, A. R., Rayens, M. K., Hall, L. A., \& Beebe, L. H. (2001). Preventing Depression in High-Risk College Women: A Report of an 18-Month Follow-Up. Journal of American College Health, 49, 299-306. http://dx.doi.org/10.1080/07448480109596316

Sakamoto, S. (1993). The Relationship between Rigidity of Self-Focused Attention and Depression. Japanese Journal of Educational Psychology, 41, 407-413. http://doi.org/10.5926/jjep1953.41.4_407

Sakamoto, S. (1997). Self-Focus and Depression: Toward an Interface between Social and Clinical Psychology. Tokyo: University of Tokyo Press.

Satoh, Y., \& Ochial, Y. (1995). The Relationship between Self-Disgust and Reflection among Undergraduates. Tsukuba Psychological Research, 17, 61-66. http://hdl.handle.net/2241/13412

Sawazaki, T., \& Matsubara, T. (1988). A Study on Mental Health of University Students (1): Results of UPI on Freshman in University of Tsukuba. Tsukuba Psychological Research, 10, 183-190. http://hdl.handle.net/2241/13136 https://doi.org/10.2132/personality.19.15

Takano, K., \& Tanno, Y. (2010). Positive Beliefs about Rumination, Self-Rumination, and Self-Reflection. The Japanese Journal of Personality, 19, 15-24.

http://doi.org/10.2132/personality.19.15

Tomoda, A., Mori, K., Kimura, M., Takahashi, T., \& Kitamura, T. (2000). One-Year Prevalence and Incidence of Depression among First-Year University Students in Japan: A Preliminary Study. Psychiatry and Clinical Neurosciences, 54, 583-588. 
http://dx.doi.org/10.1046/j.1440-1819.2000.00757.x

Trapnell, P. D., \& Campbell, J. D. (1999). Private Self-Consciousness and the Five-Factor Model of Personality: Distinguishing Rumination from Reflection. Journal of Personality and Social Psychology, 76, 284-304. http://dx.doi.org/10.1037/0022-3514.76.2.284

Submit or recommend next manuscript to SCIRP and we will provide best service for you:

Accepting pre-submission inquiries through Email, Facebook, LinkedIn, Twitter, etc. A wide selection of journals (inclusive of 9 subjects, more than 200 journals)

Providing 24-hour high-quality service

User-friendly online submission system

Fair and swift peer-review system

Efficient typesetting and proofreading procedure

Display of the result of downloads and visits, as well as the number of cited articles Maximum dissemination of your research work

Submit your manuscript at: http://papersubmission.scirp.org/

Or contact psych@scirp.org 